\title{
B.I. Грабчак
}

Академія сухопутних військ імені гетьмана Петра Сагайдачного, Львів

\section{АПРОКСИМАЦІЯ ФУНКЦІЙ АЕРОДИНАМІЧНИХ КОЕФІЦІЕНТІВ СИЛИ ОПОРУ ПОВІТРЯ МЕТОДОМ НАЙМЕНШИХ КВАДРАТІВ}

В статті досліджується питання апроксимації функиії аеродинамічних коефіиієнтів сили опору повітря при розв'язанні задач розрахунку траєкторї польоту снарядів на ЕОМ. Побудована регресійна модель, яка заснована на використанні методу найменших квадратів з апроксимачією значень функції аеродинамічних коефіцієнтів сили опору повітря лінійним поліномом і поліномом другого та вищого степенів, надані результати розрахунків коефіцієнтів регресійної моделі. Запропоновані алгоритми апроксимації функиій, заданих таблично, методом найменших квадратів та обчислення значень аеродинамічних коефіціснтів функиії сили опору повітря.

Ключові слова: апроксимація функиій, аеродинамічні коефійієнти сили опору повітря, метод найменших квадратів, степеневі поліноми.

\section{Вступ}

Постановка проблеми в загальному вигляді та аналіз літератури. Існуючі математичні моделі польоту снаряда без введення додаткових спрощень не інтегруються, тобто не може бути отримане рішення їх в квадратурах чи елементарних функціях. Це, в першу чергу, пояснюється тим, що опір середовища, в якому відбувається рух, не може бути представлений у вигляді аналітичної залежності, так як функції, які виражають силу опору повітря, задаються, як правило, таблично чи графічно [1-3]. При наявності підінтегральної функції, що не має простого аналітичного виразу, розділення змінних не є можливим, і виникає необхідність у застосуванні наближених методів. Останні розділяються на дві основні групи: наближені аналітичні методи рішення спрощених рівнянь руху та методи чисельного інтегрування систем рівнянь $[4,5]$.

Наближені аналітичні методи дозволяють знайти як загальне аналітичне рішення рівнянь руху, так i часткове рішення. Спрощення в основному зводиться до заміни дійсних значень сили опору повітря їх приближеними виразами. Аналітичні методи частіше за все використовують при дослідженнях польоту снаряда в безповітряному просторі, а також для рішення деяких задач руху снаряда в повітрі, які не потребують значної точності. Під час рішення задач теорії польоту на ЕОМ широке розповсюдження отримали методи чисельного інтегрування. На сьогоднішній день вони є основним засобом визначення параметрів траєкторій польоту снаряда [5-7].

Для того, щоб отримати аналітичні залежності, що описують великі масиви даних значень сили опору повітря, використовують методи апроксимації, які основані на тому, що масив даних замінюють функцією, яка $б$ достатньою точністю відтворювала значення сили опору повітря [6].

Маючи ряд числових значень співвідношення швидкості снаряда та швидкості розповсюдження звуку в атмосфері - чисел $M$ та відповідних значень аеродинамічного коефіцієнта сили опору повітря $c_{x}$, необхідно вивести формулу функціональної залежності $c_{x}$ від $M$, тобто встановити функцію $c_{x}=f(M)$. При цьому потрібно:

- знайти функцію, за допомогою якої кращим чином описувалась би залежність $c_{x}=f(M)$;

- визначити найбільш прийнятні числові значення коефіцієнтів, які входять у формулу, що описує шукану функцію;

- виконати аналіз точності отриманих результатів;

- якщо існує декілька видів формул, якими можна описати залежність $c_{x}=f(M)$, то відібрати на основі аналізу оптимальну, яка найкращим чином апроксимує (наближує) результати обчислень за формулою з табличними даними.

Якщо загальний вигляд формули залежності відомий наперед або може бути встановлений із теоретичних міркувань, тоді задача зводиться до визначення та оцінки точності числового значення одного або декількох параметрів залежності.

Метою статті є побудова регресійної моделі, яка заснована на використанні методу найменших квадратів 3 апроксимацією значень функції аеродинамічних коефіцієнтів сили опору повітря лінійним поліномом і поліномами другого та вищого степенів; розробка алгоритму апроксимації функцій, заданих таблично, методом найменших квадратів та алгоритму обчислення значень аеродинамічних коефіцієнтів сили опору повітря. 


\section{Основна частина}

Припустимо, що в результаті інженерного або наукового експерименту для гіпотетичного снаряда отримані значення аеродинамічного коефіцієнта сили опору повітря [1]

$$
c_{x}=f(M),
$$

які наведені в табл.

Необхідно знайти аналітичну залежність, яка б відповідала (1) та найкращим чином описувала задані значення аеродинамічного коефіцієнта сили опору повітря.

В першу чергу необхідно результати досліджень, представлених у числовому вигляді, нанести на прямолінійну координатну сітку, тобто побудувати точкову діаграму. Якщо похибки вихідних даних невеликі, то нанесені на координатну сітку точки, з'єднані ломаною або плавною лінією, одразу дадуть уяву про характер залежностей між визначеними величинами.

За видом графіка вибирають на ньому характерні ділянки. Після того, як приблизна форма кривої встановлена, залишається вияснити, графіку якої функціональної залежності в загальному вигляді вона задовольняє.

Таблиця аеродинамічних коефіціснтів сили опору повітря $c_{x}=f(M)$

Табличя

\begin{tabular}{|l|c|c|c|c|c|c|c|c|c|c|c|c|c|c|c|c|c|c|c|}
\hline$M$ & 0,1 & 0,3 & 0,5 & 0,6 & 0,7 & 0,8 & 0,9 & 1,0 & 1,05 & 1,10 & 1,20 & 1,30 & 1,40 & 1,50 & 1,60 & 1,70 & 1,80 & 1,90 & 2,00 \\
\hline$C_{x}$ & 0,154 & 0,154 & 0,154 & 0,154 & 0,154 & 0,154 & 0,229 & 0,436 & 0,459 & 0,489 & 0,437 & 0,427 & 0,417 & 0,408 & 0,398 & 0,390 & 0,379 & 0,369 & 0,359 \\
\hline
\end{tabular}

Відповідно до значень, наведених в таблиці, побудуємо графік функції $c_{x}=f(M)$, який наведений на рис. 1.

В цьому випадку характерних ділянок буде п'ять, 3 яких I, III, та V можуть бути описані лінійною залежністю [4]

$$
c_{x}=a_{1} M+a_{0},
$$

де $a_{1}, a_{0}$ - коефіцієнти лінійної функції.

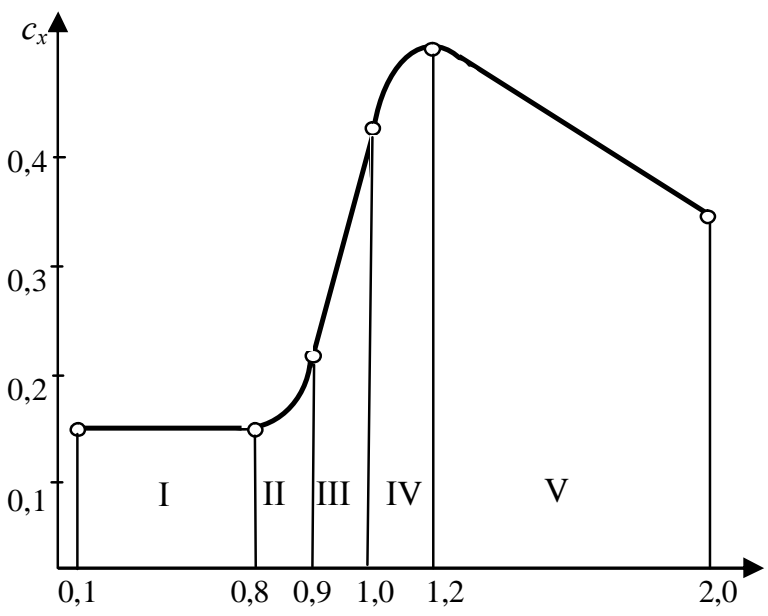

Рис. 1. Графік залежності $c_{x}=f(M)$

Одним 3 найбільш точних методів визначення параметрів функції $є$ метод найменших квадратів $[6,8]$. Але в деяких випадках можуть бути використані і більш прості методи, такі як метод середніх та інші. Якщо отримана за цим методом формула буде недостатньо точною, для подальшого iii уточнення вже може бути використаний метод найменших квадратів.

Відповідно до методу найменших квадратів коефіцієнти регресії $a_{1}, a_{0}$ лінійної залежності (2) визначаються так, щоб сума квадратів різностей значень $c_{x}$, які отримані 3 таблиці, і значеннями апроксимованої функції $c_{x}^{a n p}(M)$ була найменшою на заданій системі точок [6], тобто

$$
S=\sum_{i=1}^{n}\left[c_{x}^{a n p}(M)-c_{x_{i}}\right]^{2} \rightarrow \min ,
$$

де $S$ - середньоквадратичне відхилення між експериментальними значеннями $c_{x}$, які отримані 3 таблиці, i значеннями апроксимованої функції $c_{x}^{\text {anp }}(M) ; n$-кількість значень аеродинамічного коефіцієнта сили опору повітря.

Для розв'язання цієї задачі скористуємося загальним прийомом диференціального числення. Знайдемо часткові похідні від величини [4]

$$
S=\sum_{i=1}^{n}\left[c_{x}^{a n p}(M)-c_{x_{i}}\right]^{2}=\sum_{i=1}^{n}\left[\left(a_{1} M+a_{0}\right)-c_{x_{i}}\right]^{2}
$$

за всіма коефіцієнтами регресії $a_{1}, a_{0}$.

Визначаючи часткові похідні і прирівнюючи їх до нуля

$$
\left\{\begin{array}{l}
\frac{\partial S}{\partial a_{1}}=2 \sum_{i=1}^{n}\left[\left(a_{1} M+a_{0}\right)-c_{x_{i}}\right] M_{i}=0, \\
\frac{\partial S}{\partial a_{0}}=2 \sum_{i=1}^{n}\left[\left(a_{1} M+a_{0}\right)-c_{x_{i}}\right]=0,
\end{array}\right.
$$


отримаємо для визначення невідомих коефіцієнтів регресії $a_{1}, a_{0}$ систему лінійних алгебраїчних рівнянь (СЛАР)

$$
\left\{\begin{array}{l}
a_{1} \cdot \sum_{i=1}^{n} M_{i}^{2}+a_{0} \cdot \sum_{i=1}^{n} M_{i}-\sum_{i=1}^{n} M_{i} c_{x_{i}}=0, \\
a_{1} \cdot \sum_{i=1}^{n} M_{i}+a_{0} \cdot n-\sum_{i=1}^{n} c_{x_{i}}=0 .
\end{array}\right.
$$

Перетворимо (5) до нормального вигляду та отримуємо систему з двох рівнянь

$$
\left\{\begin{array}{l}
a_{1} \cdot \sum_{i=1}^{n} M_{i}^{2}+a_{0} \cdot \sum_{i=1}^{n} M_{i}=\sum_{i=1}^{n} M_{i} c_{x_{i}}, \\
a_{1} \cdot \sum_{i=1}^{n} M_{i}+a_{0} \cdot n=\sum_{i=1}^{n} c_{x_{i}},
\end{array}\right.
$$

розв'язавши яку знайдемо невідомі коефіцієнти регресії $a_{1}, a_{0}$.

Розв'язання СЛАР (6) знаходимо методом Крамера [4], отримані рівняння 3 такими коефіцієнтами будуть мати мінімальні квадратичні відхилення $S_{\min }$

$$
\begin{gathered}
a_{1}=\frac{\left|A_{1}\right|}{|A|}, a_{0}=\frac{\left|A_{0}\right|}{|A|}, \\
\text { де }|A|=\left|\begin{array}{cc}
\sum_{i=1}^{n} M_{i}^{2} & \sum_{i=1}^{n} M_{i} \\
\sum_{i=1}^{n} M_{i} & n
\end{array}\right|,\left|A_{1}\right|=\left|\begin{array}{cc}
\sum_{i=1}^{n} M_{i} c_{x_{i}} & \sum_{i=1}^{n} M_{i} \\
\sum_{i=1}^{n} c_{x_{i}} & n
\end{array}\right|, \\
\left|A_{0}\right|=\left|\begin{array}{cc}
\sum_{i=1}^{n} M_{i}^{2} & \sum_{i=1}^{n} M_{i} c_{x_{i}} \\
\sum_{i=1}^{n} M_{i} & \sum_{i=1}^{n} c_{x_{i}}
\end{array}\right| .
\end{gathered}
$$

Підставляючи значення таблиці в (6) та розв'язуючи (7), отримуємо співвідношення для визначення аеродинамічного коефіцієнта сили опору повітря для ділянок:

- І ділянка в проміжку $0,1 \leq M \leq 0,8$,

$$
c_{x}=0,154 \text {; }
$$

- III ділянка в проміжку $0,9 \leq M \leq 1,0$,

$$
c_{x}=2,05 M-1,615 \text {; }
$$

- V ділянка в проміжку $1,2 \leq M \leq 2,0$,

$$
c_{x}=-0,0975 M+0,554 .
$$

Виходячи $з$ того, що нам апріорі відома загальна залежність $c_{x}=f(M)$ на ділянках II, IV (див. рис. 1), використаємо регресійну модель, яку можна отримати при апроксимації табличних функцій степеневим поліномом $m$-го порядку

$$
c_{x}=a_{m} M^{m}+a_{m-1} M^{m-1}+\ldots+a_{1} M+a_{0},
$$

де $a_{m}, a_{m-1}, \ldots, a_{1}, a_{0}-$ коефіцієнти степеневого полінома.

Для апроксимації табличних значень аеродинамічного коефіцієнта сили опору повітря використаємо степеневий поліном 2-го степеня [9]

$$
c_{x}=a_{2} M^{2}+a_{1} M+a_{0},
$$

де $a_{2}, a_{1}, a_{0}$ - коефіцієнти регресії.

За аналогією для лінійних ділянок отримуємо

$$
S=\sum_{i=1}^{n}\left[c_{x}^{a n p}(M)-c_{x_{i}}\right]^{2}=\sum_{i=1}^{n}\left[\left(a_{2} M^{2}+a_{1} M+a_{0}\right)-c_{x_{i}}\right]^{2}
$$

за всіма коефіцієнтами регресії $a_{2}, a_{1}, a_{0}$.

Визначаючи часткові похідні і прирівнюючи їх до нуля

$$
\left\{\begin{array}{l}
\frac{\partial S}{\partial a_{2}}=2 \sum_{i=1}^{n}\left[\left(a_{2} M^{2}+a_{1} M+a_{0}\right)-c_{x_{i}}\right] M_{i}^{2}=0, \\
\frac{\partial S}{\partial a_{1}}=2 \sum_{i=1}^{n}\left[\left(a_{2} M^{2}+a_{1} M+a_{0}\right)-c_{x_{i}}\right] M_{i}=0, \\
\frac{\partial S}{\partial a_{0}}=2 \sum_{i=1}^{n}\left[\left(a_{2} M^{2}+a_{1} M+a_{0}\right)-c_{x_{i}}\right]=0,
\end{array}\right.
$$

отримаємо СЛАР

$$
\left\{\begin{array}{l}
a_{2} \cdot \sum_{i=1}^{n} M_{i}^{4}+a_{1} \cdot \sum_{i=1}^{n} M_{i}^{3}+a_{0} \cdot \sum_{i=1}^{n} M_{i}^{2}-\sum_{i=1}^{n} M_{i}^{2} c_{x_{i}}=0 \\
a_{2} \cdot \sum_{i=1}^{n} M_{i}^{3}+a_{1} \cdot \sum_{i=1}^{n} M_{i}^{2}+a_{0} \cdot \sum_{i=1}^{n} M_{i}-\sum_{i=1}^{n} M_{i} c_{x_{i}}=0 \\
a_{2} \cdot \sum_{i=1}^{n} M_{i}^{2}+a_{1} \cdot \sum_{i=1}^{n} M_{i}+a_{0} \cdot n-\sum_{i=1}^{n} c_{x_{i}}=0 .
\end{array}\right.
$$

Перетворимо (8) до нормального вигляду та отримуємо систему з трьох рівнянь

$$
\left\{\begin{array}{l}
a_{2} \cdot \sum_{i=1}^{n} M_{i}^{4}+a_{1} \cdot \sum_{i=1}^{n} M_{i}^{3}+a_{0} \cdot \sum_{i=1}^{n} M_{i}^{2}=\sum_{i=1}^{n} M_{i}^{2} c_{x_{i}}, \\
a_{2} \cdot \sum_{i=1}^{n} M_{i}^{3}+a_{1} \cdot \sum_{i=1}^{n} M_{i}^{2}+a_{0} \cdot \sum_{i=1}^{n} M_{i}=\sum_{i=1}^{n} M_{i} c_{x_{i}}, \\
a_{2} \cdot \sum_{i=1}^{n} M_{i}^{2}+a_{1} \cdot \sum_{i=1}^{n} M_{i}+a_{0} \cdot n=\sum_{i=1}^{n} c_{x_{i}},
\end{array}\right.
$$

розв'язавши яку, знайдемо невідомі коефіцієнти регресії

$$
a_{2}=\frac{\left|A_{2}\right|}{|A|}, a_{1}=\frac{\left|A_{1}\right|}{|A|}, a_{0}=\frac{\left|A_{0}\right|}{|A|},
$$

де

$$
|A|=\left|\begin{array}{lll}
\sum_{i=1}^{n} M_{i}^{4} & \sum_{i=1}^{n} M_{i}^{3} & \sum_{i=1}^{n} M_{i}^{2} \\
\sum_{i=1}^{n} M_{i}^{3} & \sum_{i=1}^{n} M_{i}^{2} & \sum_{i=1}^{n} M_{i} \\
\sum_{i=1}^{n} M_{i}^{2} & \sum_{i=1}^{n} M_{i} & n
\end{array}\right|,\left|A_{2}\right|=\left|\begin{array}{ccc}
\sum_{i=1}^{n} M_{i}^{2} c_{x_{i}} & \sum_{i=1}^{n} M_{i}^{3} & \sum_{i=1}^{n} M_{i}^{2} \\
\sum_{i=1}^{n} M_{i} c_{x_{i}} & \sum_{i=1}^{n} M_{i}^{2} & \sum_{i=1}^{n} M_{i} \\
\sum_{i=1}^{n} c_{x_{i}} & \sum_{i=1}^{n} M_{i} & n
\end{array}\right|,
$$


$\left|A_{1}\right|=\left|\begin{array}{lll}\sum_{i=1}^{n} M_{i}^{4} & \sum_{i=1}^{n} M_{i}^{2} c_{x_{i}} & \sum_{i=1}^{n} M_{i}^{2} \\ \sum_{i=1}^{n} M_{i}^{3} & \sum_{i=1}^{n} M_{i} c_{x_{i}} & \sum_{i=1}^{n} M_{i} \\ \sum_{i=1}^{n} M_{i}^{2} & \sum_{i=1}^{n} c_{x_{i}} & n\end{array}\right|\left|A_{0}\right|=\left|\begin{array}{lll}\sum_{i=1}^{n} M_{i}^{4} & \sum_{i=1}^{n} M_{i}^{3} & \sum_{i=1}^{n} M_{i}^{2} c_{x_{i}} \\ \sum_{i=1}^{n} M_{i}^{3} & \sum_{i=1}^{n} M_{i}^{2} & \sum_{i=1}^{n} M_{i} c_{x_{i}} \\ \sum_{i=1}^{n} M_{i}^{2} & \sum_{i=1}^{n} M_{i} & \sum_{i=1}^{n} c_{x_{i}}\end{array}\right|$.

Отже, апроксимуючі поліноми для II та IV ділянки мають наступний вигляд:

- II ділянка в проміжку $0,8 \leq M \leq 0,9$,

$$
c_{x}=0,0157 M^{2}+0,75 M-0,446 ;
$$

- IV ділянка в проміжку $1,0 \leq M \leq 1,2$,

$$
c_{x}=-1,4908 M^{2}+3,2824 M-1,3421 .
$$

Таким чином, загальний вигляд залежності $c_{x}=f(M)$ для I-V ділянок дорівнює

$$
c_{x}=\left\{\begin{array}{lr}
0,154, & 0,1 \leq M \leq 0,8 \\
0,0157 M^{2}+0,75 M-0,446, & 0,8 \leq M \leq 0,9 \\
2,05 M-1,615, & 0,9 \leq M \leq 1,0 \\
-1,4908 M^{2}+3,2824 M-1,3421 & 1,0 \leq M \leq 1,2 \\
-0,0975 M+0,554, & 1,2 \leq M \leq 2,0
\end{array}\right.
$$

За умови наперед заданої точності апроксимації табличних функцій аеродинамічних коефіцієнтів сили опору повітря, вираз (3) прийме вигляд

$$
S=\sum_{i=1}^{n}\left[c_{x}^{a n p}(M)-c_{x_{i}}\right]^{2} \leq \varepsilon,
$$

де $\varepsilon$ - задана похибка отриманих результатів.

Блок-схема алгоритму апроксимації функцій $c_{x}=f(M)$, заданих таблично, методом найменших квадратів, наведена на рис. 2.

Якщо для заданого степеня $m$ полінома $c_{x}$ в результаті розрахунків на ЕОМ отриманий поліном не відповідає заданій похибці обчислень $\varepsilon$, то необхідно збільшити степінь полінома на 1 (тобто степінь полінома буде $m+1)$, при цьому на одиницю збільшується кількість коефіцієнтів полінома (додається новий член степеневого полінома), які необхідно знову розраховувати. При цьому вираз (8) збільшується на один порядок, i для визначення нових коефіцієнтів $a_{m}, a_{m-1}, \ldots, a_{1}, a_{0}$ необхідно знову розв'язувати нову систему (10) 3 додаванням ще одного рівняння. Цей процес повторюється доти, поки не виконається умова (13).

Застосування способу апроксимуючих поліномів $\epsilon$ більш переважним порівняно зі способом вводу в пам'ять ЕОМ великих за об’ємом таблиць та програм лінійної чи квадратичної інтерполяції. Обчислення значень функції вимагає лише невеликих за об'ємом таблиць коефіцієнтів відповідних поліномів.
Блок-схема алгоритму обчислення функції $c_{x}=f(M)$ наведена на рис. 3.

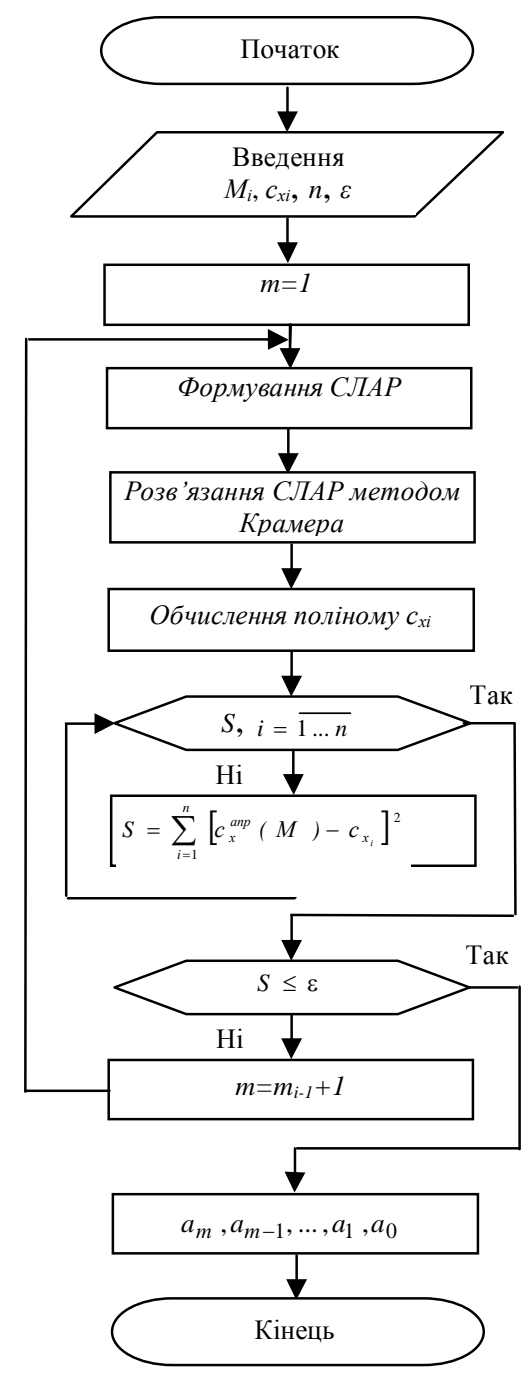

Рис.2. Блок-схема алгоритму апроксимації функції $c_{x}=f(M)$, заданої таблично, методом найменших квадратів

Для забезпечення необхідної точності отриманих розрахунків програма обчислень значень функції $c_{x}=f(M)$ повинна вирішуватися для $M=0,1 \ldots 2,0$ 3 кроком 0,05 [7].

\section{Висновки}

У статті проведено дослідження питання апроксимації функції аеродинамічних коефіцієнтів сили опору повітря при вирішенні задач розрахунку траєкторії польоту снарядів на ЕОМ. Побудована регресійна модель, яка заснована на використанні методу найменших квадратів з апроксимацією значень аеродинамічних коефіцієнтів сили опору повітря лінійним поліномом і поліномами другого та вищого степенів, представлені результати розрахунків коефіцієнтів моделі.

Запропоновані алгоритми апроксимації функцій, заданих таблично, методом найменших квадратів, i визначення значень аеродинамічних коефіцієнтів опору 


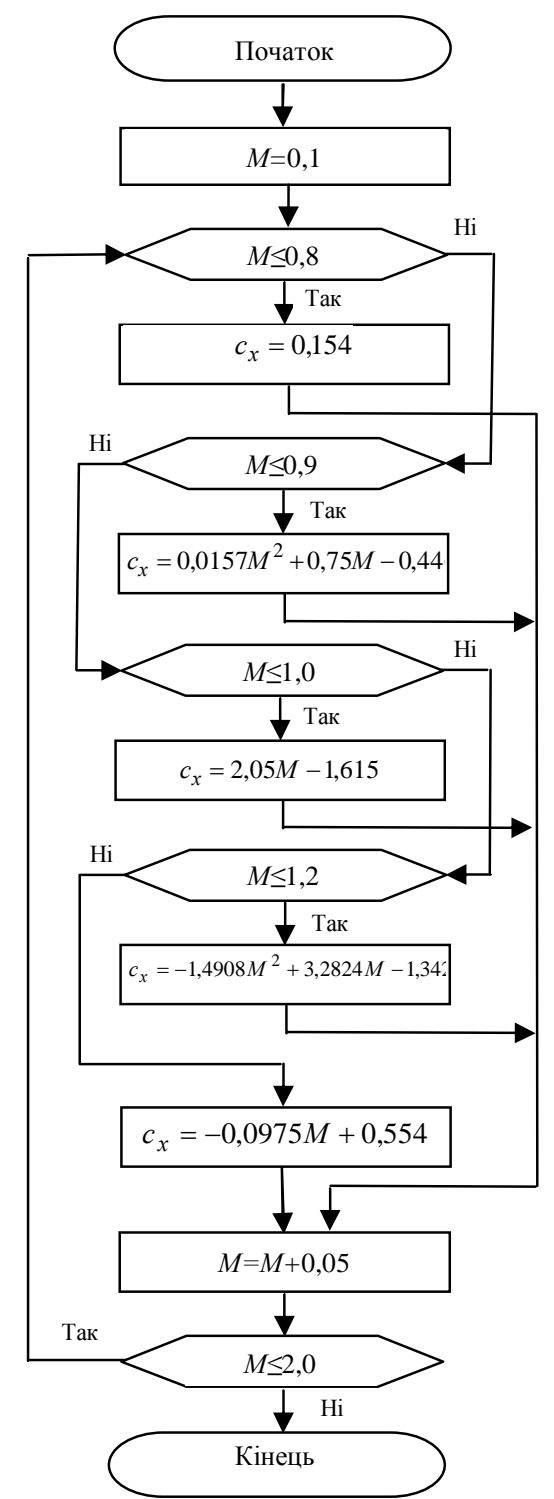

Рис. 3. Блок-схема алгоритму обчислення функції $c_{x}=f(M)$ повітря, що використовуються для розрахунку траєкторії польоту снарядів, дозволяють зберігати у пам'яті ЕОМ невеликі за об'ємом таблиці коефіцієнтів відповідних поліномів порівняно з великими за об'ємом таблицями та програмами лінійної чи квадратичної інтерполяції.

Перспективним напрямом подальших досліджень $\epsilon$ оцінка точності запропонованих підходів апроксимації функції аеродинамічних коефіцієнтів сили опору повітря.

\section{Список літератури}

1. Равдин И.Ф. Внешняя баллистика неуправляемых реактивных снарядов / И.Ф. Равдин. -Л.: ВАА, 1972. - 184 c.

2. Внешняя баллистика. Кн. 1. - М.: ВАИА им. Дзержинского, 1954. - 463 c.

3. Внешняя баллистика. Кн. 2. - М.: ВАИА им. Дзержинского, 1954. - 496 c.

4. Дубовик В.П. Вища математика / В.П. Дубовик, I.I. Юрик. - Київ: А.С.К., 2006. - 648 c.

5. Лисенко В.М. Теорія польоту / В.М. Лисенко, В.І. Грабчак, Д.А. Новак. - Суми: СумДУ, 2006. - 203 с.

6. Калиткин Н.Н. Численные методы / Н.Н. Калиткин. М.: Наука, 1978. - 512 c.

7. Дмитриевский А.А. Внешняя баллистика / А.А. Дмитриевский, Л.Н. Лисенко. - М.: Машиностроение, 2005. $-607 c$.

8. Трауб Дж. Итерационные методы решения уравнений / Дж. Трауб. - М.: Мир, 1985. - 263 c.

9. Суетин П.К. Классические ортогональные многочлены / П.К.Суетин. - М.: Наука, 1976. - 327 с.

Рецензент: д.т.н., с.н.с. М.Ю. Яковлев, Академія сухопутних військ імені гетьмана Петра Сагайдачного, м. Львів.

\section{АППРОКСИМАЦИЯ ФУНКЦИЙ АЭРОДИНАМИЧЕСКИХ КОЭФФИЦИЕНТОВ СИЛЫ СОПРОТИВЛЕНИЯ ВОЗДУХА МЕТОДОМ НАИМЕНЫШИХ КВАДРАТОВ}

В.И. Грабчак

В статье исследуются вопроси аппроксимации функиии аэродинамических коэффициентов силь сопротивления воздуха при решении задач расчета траекторий полета снарядов на ЭВМ. Построена регрессионная модель, основанная на использовании метода наименьших квадратов с аппроксимацией значений функиии аэродинамических коэффициентов силь сопротивления воздуха линейным полиномом и полиномом второй и высшей степеней, представленные результаты расчетов коэффичиентов регрессионной модели. Предложены алгоритмы аппроксимации функиий, заданных таблично, методом наименьших квадратов и расчета значений аэродинамических коэффициентов функичи силь сопротивления воздуха.

Ключові слова: аппроксимаџия функиий, аэродинамические коэффициенты силы сопротивления воздуха, метод наименьших квадратов, степеннье полиномь.

\section{APPROXIMATION OF AIR RÉSISTANCE AERODYNAMIC COEFFICIENTS USING THE LEAST SQUARE METHOD \\ V. Hrabchak}

Problems of function of air resistance approximation when calculating shell flight trajectory on computers are examined in the article. Regression model, based on employment of least square method with air resistance value of function approximation by linear polynomial and polynomial of the second and highest order has been developed, results of calculations of regression model indexes have been presented. Algorithms of tabulated function approximation by of least square method and calculations of aerodynamic indexes of air resistance function have been presented.

Keywords: approximation function, air resistance aerodynamic indexes, least square method, power polynomials. 